\title{
DESIGN FOR MANUFACTURING AND ASSEMBLY AND CAE TOOls - THE CASE OF A Rice HUSKER
}

\author{
PINZON, R.; LASCANO, S. \& MAURY-RAMIREZ, H.
}

Abstract: This paper presents an advantageous and newfangled approach where the combination of Design for Manufacture and Assembly concepts and product architecture principles, are complemented with CAE tools, in order to reduce the manufacturing costs, time to market and improve the design deliverables quality of a mechanical system. The proposed contributions were validated applying them on a rice husker design. Some novelty concepts as hot/warm/cold swapping were taken from electronics field to the mechanical system design obtaining advantages in the overall product lifecycle.

Key words: Design for Manufacturing and Assembly (DFMA), product architecture, Design for X - DFX and CAE tools
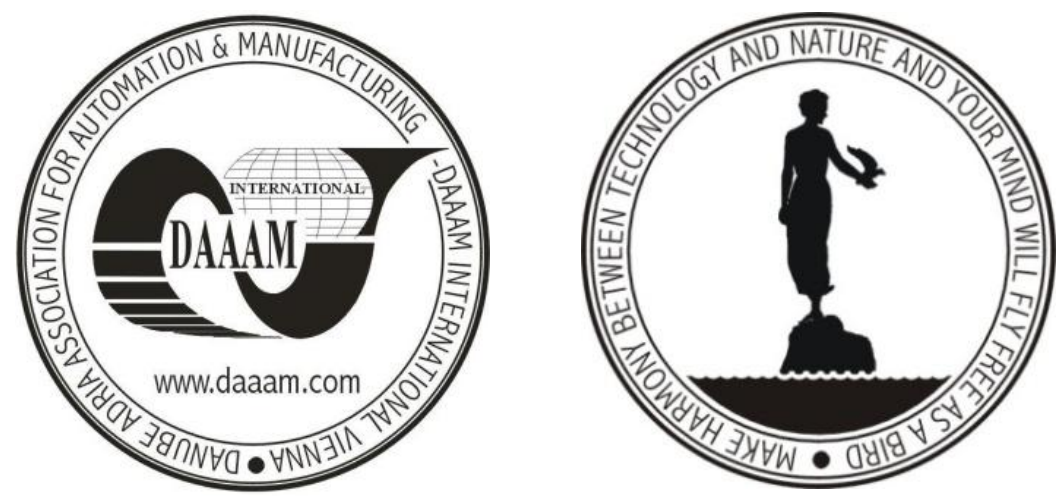

Authors' data: Eng. Pinzon, R[oger]; Ph.D. Lascano, S[heila]; Ph.D. MauryRamirez, H[eriberto], Universidad del Norte, Km 5 Via Puerto Colombia, Barranquilla, Colombia, rpinzon@uninorte.edu.co, hmaury@uninorte.edu.co

This Publication has to be referred as: Pinzon, R[oger]; Lascano, S[heila] \& Maury-Ramirez, H[eriberto] (2012). Design for Manufacturing and Assembly and CAE Tools - The Case of a Rice Husker, Chapter 53 in DAAAM International Scientific Book 2012, pp. xxx-xxx, B. Katalinic (Ed.), Published by DAAAM International, ISBN 978-3-901509-86-5, ISSN 1726-9687, Vienna, Austria

DOI: $10.2507 /$ daaam.scibook.2012.53 


\section{Introduction}

The rice production is divided into three steps: harvest, post harvest, and rice processing. Each of these steps is further subdivided into the necessary activities to achieve the required quality of the rice.

Parboiling and milling are the main rice processing activities. Parboiling is a hydrothermal treatment of rough rice prior to milling. In the parboiling process, rough rice is soaked, steamed and re-dried before milling. Rice milling involves the removal of hulls and bran from rough rice to produce polished rice (De Datta, 1981). A great quantity of rice is lost during the milling process; therefore, milling requires careful planning and use of properly designed equipment.

The milling equipment, often referred to as husker, dehusker, huller or sheller, removes the husk from the grain. The most common types of husker use a rotating steel dehuller covered with a rubber shell. The rubber roll paddy husker consists of two closely spaced rubber rollers rotating in opposite directions at different speeds, one roll moves about 25\% faster than the other (Wimberly, 1983). The rubber rollers contact creates a shearing action on the falling rough rice, which removes the husk from the grain (Fig. 1).

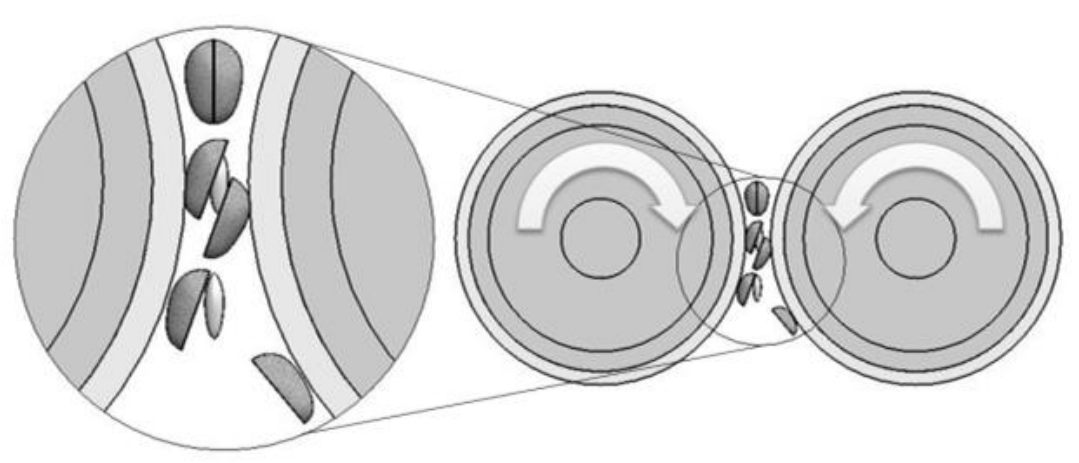

Fig. 1. Description of a rubber roller rice husker

As a result of the economy globalization, hyper-competency and the fast market changes, manufacturers worldwide are being forced to find ways to improve their product portfolio flexibility and time to market without affecting the manufacturing cost and product performance.

Colombia has an emerging economy, with a wide knowledge in rice production. Such knowledge has been taken by some local companies to manufacture and to export rice production machinery. In spite of this knowledge, Colombian machinery manufacturers, must be prepared to face the dynamics of the new global market, hence these companies are making enormous efforts to innovate and be competitive to global scale.

For the rice machinery manufacturers, the use of new design methods and tools is essential to meet the required competence levels along the product lifecycle (Raymond, et al., 2009; Farias et al., 2006). Among the wide variety of design tools, the Design for X (DFX) methods are an attractive option for manufacturers. DFX is the generic name for the members of the family of methodologies adopted to improve product design as well as design process from a particular perspective which is 
represented by X (Huang, 1996). According to Tichem (1997), a number of different interpretations of $\mathrm{X}$ exists. The $\mathrm{X}$-either represents:

- A specific property (e.g., cost, quality, lead time, efficiency, flexibility, risk or environmental effects).

- A life - cycle phase of the product (e.g., parts manufacturing, assembly, distribution, service or discarding) or one of the sub-processes (e.g., gripping or feeding).

This paper presents some novel design concepts applied on the rice husker design in an industrial collaboration with a Colombian company, leader in the provision of industrial facilities for rice processing. The relevant results are discussed here.

\section{Initial Design of Rubber Rollers Rice Husker}

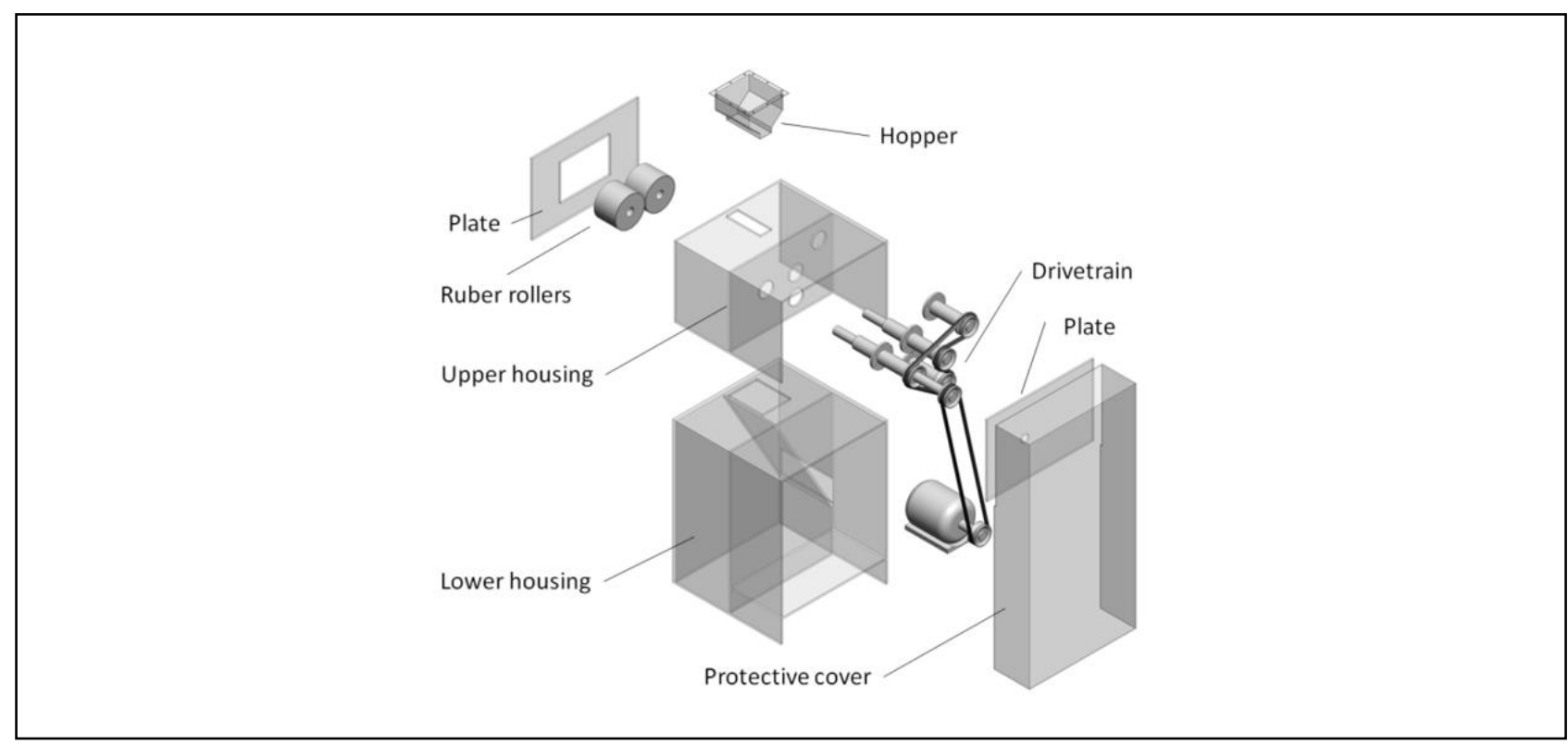

Fig. 2. Simplified scheme of the rubber rollers rice husker

The roller-type husker is one of the less bulky (Gariboldi, 1988). However, the Company's original design was still heavy and complex due to the high number of mechanical parts, derived from the effort to obtain a single drive motor and selfadjustable roller space (Fig. 2). The initial configurations of the belt transmission system and the roller space adjustment system exhibited clear improvement opportunities.

The drive train configuration was designed to provide an appropriate angular velocity and properly movement direction to each shaft and its corresponding rubber roller. Additionally, the heavy husker structure of the original design offered further improvement opportunities, because it was manufactured with high thickness welded steel plates.

The upper housing was divided into two sections, one of them enclosed the rubber rollers and the other enclosed the system of pulleys. 
The section that enclosed the rollers isolated them from the environment for cleanliness and safety. The roller feeding plate is very important by its ability to spread and to feed a paddy curtain on rollers continuously. Finally, the lower housing was used mainly to support to the mechanical system components.

\section{Methodology}

A methodology of three phases was applied (Fig. 3), it began with the development of the overall system CAD model. The original CAD model was provided by the manufacturer. The $\mathrm{CAD}$ model contained enough product information such as features, materials, surface finishing, weights and critical dimensions, among others. The application of the described methodology, allowed the design team to identify the improvement opportunities.

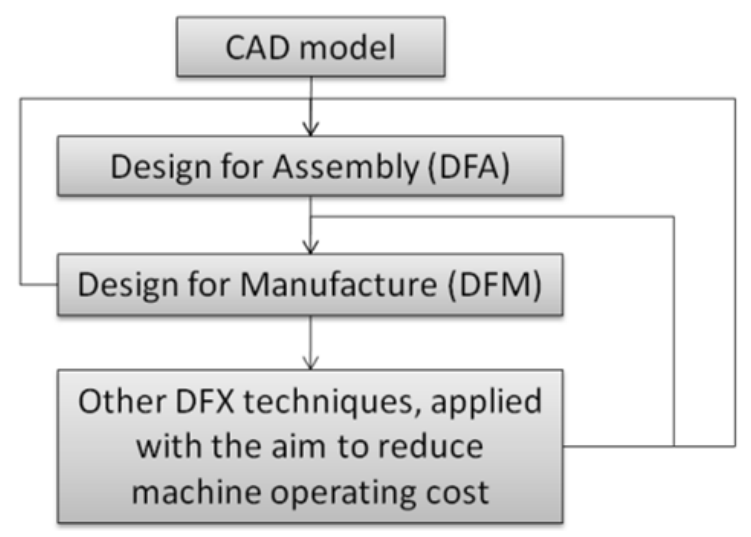

Fig. 3. Implemented methodology

The first phase consisted on applying the DFA (Design for Assembly) guidelines, whose aim is to minimize the effort in the product assembly. According to Bralla (1986), the most significant benefits of DFX techniques, come from Design for Assembly (DFA). DFA simplifies the product and reduces the parts number, making it more efficient the product's manufacturing and its assembly. The two main objectives of DFA are to reduce the number assembly operations like the amount and variety of tools and parts used, and finally, to make easy the parts handling (Greer et al., 2004).

DFA has incidence both the product structure like the part connections (Reader Poll, 1993). In this project, the DFA guidelines were verified executing some assembly and disassembly operations.

The second phase consisted to apply the DFM (Design for Manufacturing) guidelines, to rationalize the product configuration from a manufacturing perspective. DFM focuses on two design issues: the proper selection of a manufacturing processes chain for a component and, the optimization of the part geometry design for the selected processes chain. In both situations, two points are analyzed: the part geometry-manufacturing process compatibility and the optimization of issues like cost, flexibility, environmental impact, etc. DFM affects both, the overall product structure and its parts. 
Assembly and Manufacture guidelines do not always converge, sometimes, assembly guidelines lead to impractical designs by their technical difficulties and high costs. Therefore, an integral approach is convenient through the DFMA method (Design for Manufacturing and Assembly). DFMA finds the equilibrium point between the manufacturing and assembly, Indentifying infeasible geometries or costly designs at early design phases.

Although DFA and DFM were applied separately and sequentially, feedback from each step allowed mutual their interaction. DFA results were presented and discussed with the manufacturer from a technical point of view, considering also the functional and manufacturing product limitations. The manufacturer insights were also used to make specific changes over the results previously obtained with the DFA guidelines.

Additionally to DFMA guidelines, new concepts were implemented to reduce the operating and maintenance costs of the husker. Specifically, new concepts or design rules were proposed for the interface design; these concepts were validated on the interface design between the rollers and their supporting driving shafts. The concepts of Cold Swapping and Hot Swapping, brought from electronics and software fields, were applied to the husker interface design. These concepts must be defined and adapted for the mechanical systems, and therefore, the following design rules were defined, considering two replacement scenarios, the not running replacement and running replacement.

- In the first scenario, Cold Swapping architecture interface have to be used. The use of such interface implies that for a safe replacement of components, hard modules or subsystems, the system must be turned off. Hence, the modules replacement is not possible without the production interruption. A mechanical coupling could be used to represent this interface kind.

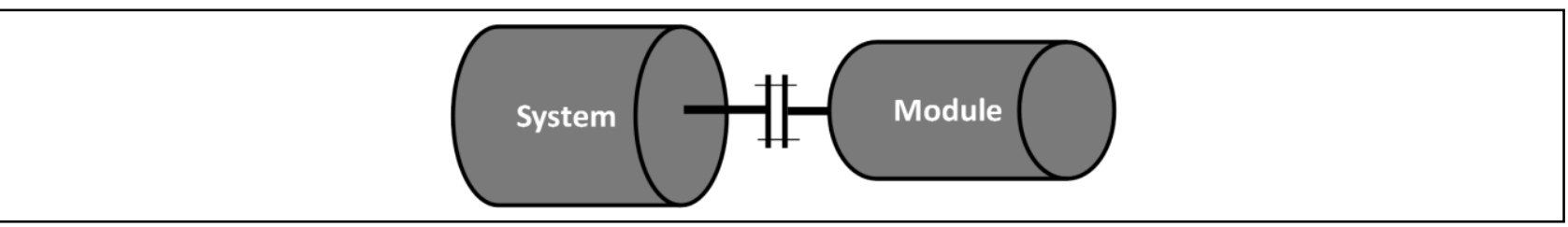

Fig. 4. Representation of a "Cold Swapping" interface type

For the husker case, a conical area was used on the shaft ends, making it faster the insertion of the rollers and ensuring torque transmission due to interference, this interface design is similar to pin coupling. For an easier disassemble of rollers, three screwed holes were added.

- In the second scenario, Hot Swapping architecture interface must be used. In this type of architecture, the insertion or replacement of any part or mechanical subsystem could be completed without the production interruption, while the system casing remains closed. Therefore, this type of interface will be implemented in the next husker generation. An application of this concept in a mechanical system is shown in Fig. 5. It is necessary a mechanical clutch to connect and disconnect the operating module without stop. In addition, for the insertion of the replacement module, a turning table has to be installed, thus 
ensuring the operability of the system. The operation of the turning table could be manual or motorized with automatic control.

- An intermediate interface kind was also proposed, "Warm Swapping", although, it was not implemented for this husker generation. The breakdown time to overcome inertial loads (electrical, mechanical or thermal) and to restore the system operation are shorter than Cold Swapping's, but longer than Hot Swapping's.
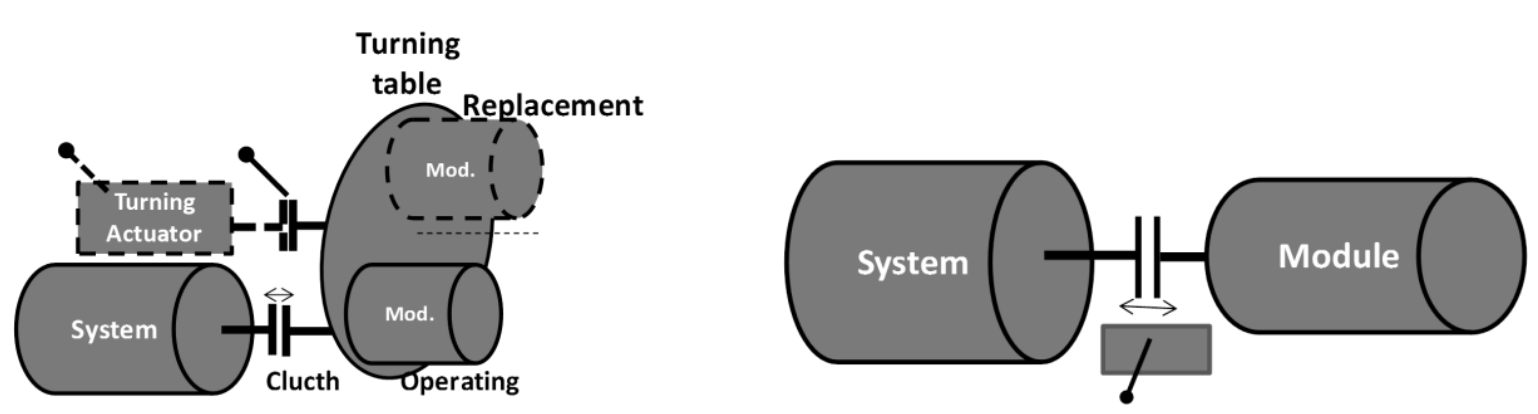

Fig. 5. (Left) Schematic representation of a "Hot Swapping" interface architecture type. (Right) Schematics representation of a "Warm Swapping" interface architecture type

\section{Results}

The methodology application reduced the number of parts, producing a snowball effect on cost reduction due to the reduction of required drawings and engineering specifications, stocks and suppliers quantities were also beneficially affected. These factors had a strong impact on manufacturing costs, obtaining great benefits to the final user.

Some design guidelines suggested an approach to functional modularity and part integration with the purpose to reduce the part number, others recommend minimize the variety to simplify the product design, the manufacturing and its assembly. In the same way, revising the compatibility and economy of manufacturing processes to meet the geometrical and functional requirements is mandatory, also like the CAE tool application to guarantee the system structural integrity.

CAE tools (FEA) supported the decision making of plate thickness reduction in the husker upper case up to a thickness value able to maintain the reliability and system integrity. The required welded joints and their adverse effects were minimized as consequence of these changes. The upper case was produced like an entire box using CNC press technologies with a significant reduction of times and manufacturing costs.

With less welding joints some drawbacks like the joint preparation, the welding cleaning, residual stresses and heat distortions were mitigated. It was reached a manufacturing cost reduction close to $39 \%$, without undermining the structural product performance (see table 1).

Although the developed casing geometrical complexity was higher, the CNC sheet metal forming technologies made it straightforward to overcome these manufacturing difficulties. The case corner radii increments leaded to reduce the 
stress risers. The less amount of welded joints, improved the fatigue performance of the device. CAE tools and accumulative fatigue damage models were used to compute the residual life.

The rearrangement of the driving system is another enhancement made through the use of the methodology. The driving system was integrated to the processing module and the lower housing and a bottom pulley were suppressed (see fig. 6).

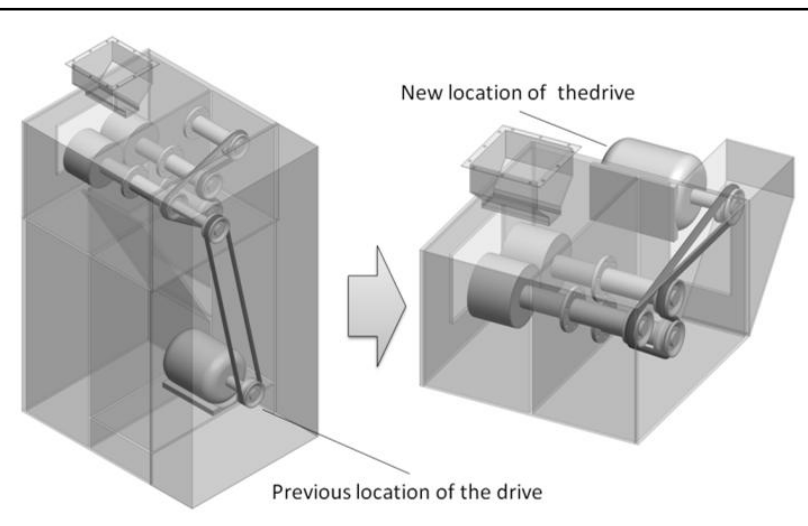

Fig. 6. Description of the new location of the drive.

The belt transmission system simplification and the standardization of components reduced the part number and variety, minimizing the Pugh's complexity index (Riba 2002). The last, allowed the reduction of the product assembly tool variety. The efforts required for the management of purchasing were also diminished.

One of the major drawbacks during costs reduction evaluation was the lack of reliable data, specifically data related to the times required for manufacturing and assembly of single parts. Some authors have proposed models for time estimation, which are mainly based on geometrical features of the components (Boothroyd, G., Dewhurst, P., \& Knight, W. 2002). Such models are limited to small and medium size components, not relevant to the range of sizes handled in the embodiment of the rice husker.

To overcome these limitations, it was necessary the direct measurement of the time consumption for relevant manufacturing operations. These measurements were complemented by a detailed computation of material consumption, time and assembly operations for several components.

Tab. 1. summarizes the percentage of improvements achieved by the iterative use of the methodology; different metrics were used to measure the impact of the methodology.

\begin{tabular}{|l|c|c|c|}
\hline \multicolumn{1}{|c|}{ Description } & Original design & Redesign & Improvement (\%) \\
\hline Assembly Theoretical time (h) & 1,71 & 1,32 & $22,8 \%$ \\
\hline Number of different parts & 193 & 136 & $29,5 \%$ \\
\hline Total number of parts & 446 & 230 & $48,4 \%$ \\
\hline Total number of operations & 1845 & 951 & $48,5 \%$ \\
\hline Metal fabrication time (h) & 65,1 & 39,3 & $39,6 \%$ \\
\hline Weight (Kg) & 390,7 & 284,7 & $27,1 \%$ \\
\hline
\end{tabular}

Tab. 1. Comparison of original and new designs of the processing machine 
The achieved improvements affected the overall embodiment costs. These costs were influenced in three aspects: the first, the reduction of $7 \%$ in raw material acquisition with the DFMA methodology. The manufacturing cost reduction of 39\% was the second, and the third was an assembly cost reduction close to $26 \%$.

The impact on the system maintainability was difficult to measure, although important benefits are expected in relation to the spare part acquisition by the component standardization. For final users, standardization allows dealing with local suppliers instead of having a unique international supplier and a large spare inventory.

\section{Example of the methodology applied to a single piece}

In table 1 it is shown that 193 different parts from the original design were analyzed, one of the most important parts of the system was the case frame where all machine pieces were supported.

Figure 7, depicts the structural evaluation of the original design of the frame, which is composed by two metal sheets, welded one to each other. After the use of DFMA guidelines, one of the modifications was the use of a single metal sheet instead of two of them. The improvement of the case, its stiffness and the stresses reduction were determined with FEM-CAE tools. As the joining and connection characteristics are very important on the product costs, the main recommendation was to reduce the welded joints because these have adverse consequences (Riba, 2002).

The welding processes of the original design required more time and consumables. According to the structural analysis of the new frame, an optimum and thinner thickness was obtained, improving the overall system performance (see fig. 8 ). The new thickness costs were compared with the previous design, obtaining a considerable cost reduction of $23.1 \%$. The assembly time reduction was $53 \%$.

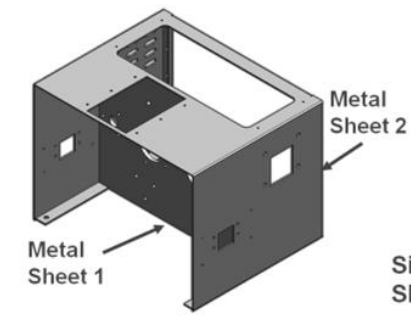

(a)

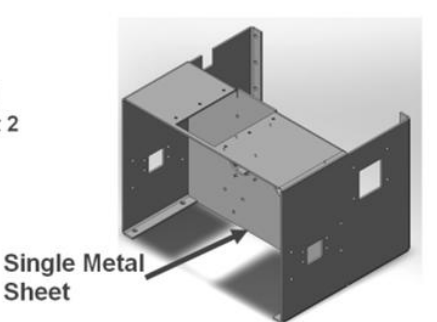

(b)

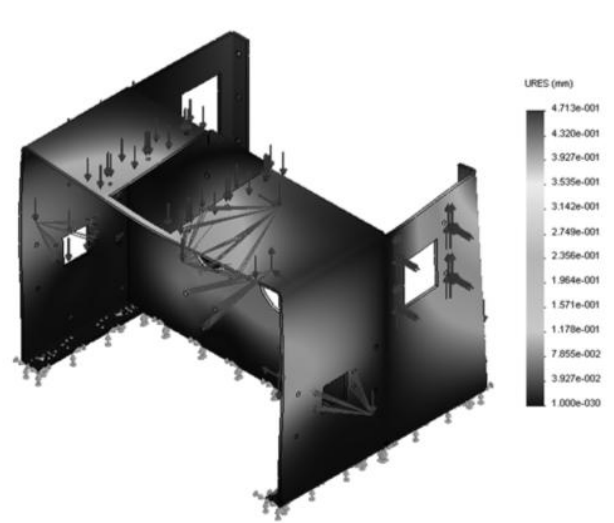

(d)

(c)

Fig. 7. (a) The original frame design composed of two metal sheets. (b) The new frame design is composed of a single metal sheet. (c) Extended metal sheet of the new design. (d) Augmented deformation of the frame during operation (scale: 68.2). A maximum displacement of $0.4 \mathrm{~mm}$ was found in the bottom part of the frame 


\section{Conclusions}

Design for Manufacturing and Assembly leads to simplification and standardization of design and manufacturing processes. The function integration and the shape optimization simplify the system assembly and the workflow. The obtained results verify the importance of using these methodologies from early design phases and their high impact on committed costs.

The achieved improvements, affected the overall embodiment costs. The costs were influenced in three aspects; the first was the raw material acquisition in which a reduction of $7 \%$ was reached. The second was a manufacturing cost reduction of $39 \%$, while the third was the assembly cost reduction of $26 \%$.

The use of CAD/CAE tools was essential for a successful application of the methodology. The aid of software allowed studying different assembly sequences and detecting implementation issues derived from the suggested changes. The participation of experts contributed to avoid misunderstandings related to some piece functions.

Although the DFA guidelines can lead to a cheaper design, the complexity of some pieces and the integration of functions may increase the service costs. These problems can be avoided by making an iterative analysis of the assembly-disassembly procedures in a CAD 3D software at early stages of the design.

Some changes may affect the structural performance or even the machine function itself, therefore special care must be taken. Some analytical tools (CAE) as FEM should be used to predict the subsequent behaviour of the system.

An interesting approach to integrate the design, manufacturing and assembly has been shown along with relevant results. A convergence point between the product architecture and DFMA methods was verified, specifically in the design of the architecture interfaces. The interfaces have a significant impact on the assembly and disassembly times. Some novel concepts as hot/warm/cold swapping were adapted from electronics field to mechanical system design, those from a perspective of lifecycle design were represented and defined.

Future works of the research team are focused on the development and validation of methodologies for the design of platform-based reconfigurable products. This approach gives the companies the opportunity to satisfy individual customer needs by an expansion of the product lines, concentrating the most variable and significant customer needs, in a few functional modules.

\section{References}

Barnes, C., Jared, G., \& Swift, K. (2004). Decision support for sequence generation in an assembly-oriented design environment. Robot Comput Integr Manuf , 20, 289-300

Boothroyd, G., Dewhurst, P., \& Knight, W. (2002). Product Design for manufacture and Aseembly (Second Edition ed.). New Yory, NY: Marcel Dekker

Bralla, J. (1986). Design for assembly. Design for manufacturability handbook. New York: Mc Graw Hill 
De Datta, S. (1981). Principles and Practices of Rice Production. Singapore: John Wiley \& Sons

Farias, P., Aca, J., Molina, A., Maury, H., \& Riba, C. (2006). Evolución de los modelos del proceso de diseño. In C. Riba, \& A. Molina, Ingeniería Concurrente: Una visión integradora (pp. 21-36). Barcelona: Ediciones UPC

Gariboldi, F. (1988). Rice Milling equipment, operation and maintenance. Rome: Food and Agricultural Organitations (FAO) of the United Nations

Greer, J., Jensen, D., \& Wood, K. (2004). Effort flow analysis: a methodology for directed product evolution. Design Studies , 25 (2), 193-214

Howard, C. (1992). Handbook of Modern Welding (Vol. III)

Huang, G. (1996). Design for X: Concurrent Engineering Imperatives. Berlin: Springer

Karger, W., \& Bayha, F. (1966). Engineered Work Measurement. New York, NY: Industrial Press, Inc

Lucas Engineering Systems Ltd. (1993). Design for manufacture and assembly practitioners manual Version 10 . University of Hull

Maury, H., Niebles, E., \& Torres, J. (2009). Diseño para la fabricación y ensamblaje de productos soldados (Design for Manufacture and Assembly of welded products). Barranquilla: Ediciones Uninorte

Miyakawa, S., \& Ohashi, T. (1986). The Hitachi assemblability evaluation method (AEM). Proceedings of the first international conference on product design for assembly. Newport

Ostwald, P. (1986). AM Cost Estimator. New York, NY.: Mc Graw Hill

Otto, K., \& Wood, K. (2001). Product Design: Thechniques in reverse Engineering and new Product Development. New Jersey, NY.: Prentice Hall

Raymond, H., Barnes, \& Catherine. (2009). Towards an integrated approach to "Design for X": an agenda for decision-based DFX research. Research in Engineering Design

Reader Poll. (1993). Computer-Aided Engineering

Riba, C. (2002). Diseño Concurrente. Barcelona: Ediciones UPC

Serrano, J., Bruscas, G. M., \& Romero, F. (2006). Diseño para fabricación y montaje. In C. Riba, \& A. Molina, Ingeniería Concurrente: Una metodología integradora (pp. 107-122). Barcelona: Ediciones UPC

Stone, R., McAdams, D., \& Kayyalethekkel, V. (2004). A product architecture-based conceptual DFA technique. Design Studies , 25 (3), 301-325

Tichem, M. (1997). Design Coordination Approach to Design for X. Delft, The Netherlands: Delft University Press

Tomiyama, T., Gu, P., Jin, Y., Lutters, D., Kind, C., \& Kimura, F. (2009). Design Methodologies: Industrial and educational applications. CIRP Annals Manufacturing technology (58), 543-565

Welding handbook - INDURA. (2006)

Wimberly, J. (1983). Technical handbook for the Paddy Rice Postharvest Industry in Developing Countries. Manila, Philippines: International Rice Research Institute

Yoosufani, Z., Ruddy, M., \& Boothroyd, G. (1983). Effect of Part Symmetry on Manual Assembly Times. J. Manuf 